\title{
Effect of Gender, T.V.watching, Father Occupation and Science Resources available at home on Science Achievement of Secondary School Students of Central U.P.
}

\author{
Gyan Pratap Singh ${ }^{1}$, Dr. Ali Imam ${ }^{2}$ \\ ${ }^{1}$ Research Scholar, Faculty of Education, Integral University, Lucknow (India) \\ ${ }^{2}$ Associate Professor, Faculty of Education, Integral University, Lucknow (India)
}

\begin{abstract}
This study explored the effects of gender, t.v.watching, father occupation and science resources available at home on science on science achievement. A convenience sample of 2006 students, 1080 males and 926 female from twenty one schools of central UP was used for study. The Science Attitude Scale, Science Achievement Test and Personal and Environmental background assessment questionnaire were used for data collection, while t-test, f-test and correlation techniques were used for statistical analysis. The results revealed that there was a significant difference between science achievement of boys and girls. The results show that the duration of television watching was found to affect positively the science achievement of students at a certain time interval. The analysis also showed that the Science achievement was positively influenced by father's occupation. Further the results showed that the availability of science resources at home was positively correlated with the science achievement of the students.
\end{abstract}

Key Words: Science Achievement, Gender, T.V.watching, Father Occupation and Science Resources available at Home.

\section{INTRODUCTION}

Education on all accounts is accepted to be a systematic and applied discipline. It is systematic because it draws heavily upon other discipline. It is applied because educational ideas have to be practiced before they could gain proper acknowledgement and accuracy. It raises the status of the human beings and the community as a whole. It broadens the mental horizon of the human beings.

Education involves the transfer of communication of information knowledge and skills from one point (The source) to another (The Receiver). According to M.K. Gandhi "Education Means the all round drive out the best in child, man, body, Mind and Soul.

Education is universally recognized as the most effective tool of bringing about change towards the social and economic betterment and cultural transformation of a society. It raises the status of human being and the country as a whole. It broadens the mental horizon of the human being. In one hand education develops the total personality of the individual; on the other hand it contributes to growth and development of the society. It is only through education the moral ideas and spiritual values, the aspiration of the nation and its cultural heritage are transferred from one generation to another for preservation, purification and sublimation into higher and higher culture.

Education and training play a vital role in assisting individuals and societies to adjust to social, economic and cultural changes and promote the development of the human capital essential for economic growth. Modern education, schooling in particular, aims at imparting knowledge, skills and attitudes required by the young ones to become functional in their respective societies. Schools are therefore intended to serve as agents for developing individual citizens within a country (Pandey 1996:77). In essence, schools are institutions where children are groomed to appreciate what the society in which they live stands for and are equipped in order for them to contribute to the advancement of their society.

The nation that fails to make a genuine assessment of his human energy available in it is bound to lag behind others in the era of great competition in the national and international fields. An ideal system of education should enable individuals to know and develop to the fullest their physical and intellectual potentialities and promote their awareness of societal and human values so that they can develop a strong character and live better lives and function as responsible members of society.

Science and Mathematics have become a substantial and integral part of an organized society. There is a close interaction between Science and Mathematics and the economic, social, political and educational issue of the society, therefore, there is hardly and need to justify the place of Science in a scheme of general education for school children. The objectives of Science teaching at secondary level as spelt out by the NCERT (1988), clearly indicates, "that the basic purpose of Science education at 
secondary level is to understand the nature of Science, its processes, methods and scope, so that the students can use scientific method to solve their problems and develop scientific attitude". Another important objective of secondary school Science is to provide a sound foundation for those seeking to continue the study of Science at higher level. According to Kothari (1968-66), "the aim of teaching Science in the primary school should be to develop proper understanding of facts, concepts, principles and processes in the physical and biological environment". The purpose of Science education at primary stage shouldn't be to stuff the minds of the children with facts and information, but to sharpen their senses to enable them to observe there is said that science education in the schools should make a revolution in attitudes and interest of children. In the words of Irwin L. Ramsay (1968) "We are living in a world of change and challenge a world Filled with stocking and awe inspiring discoveries as well as world filled with crumbling of moral rot and decay." Such a time with its fast tempo has many implications for science education, unimagined higher to especially for a developing country like India.

Science has responded to human concerns in several areas like medicine and agriculture. The technological developments have reduced drudgery for a considerable sector of the population. In future, however, the side effects of the developments and developmental activities which alienate human society from nature will have to be seriously responded to. Every individual will require training and preparedness in areas like disaster management. Need based knowledge would be valued by the society and the community.

In the present social set-up, science is more important for the common man. A little reflection will show what predominant role science plays in our everyday life and how it has become an indispensable factor for the progress of our present day world. It is the pivot of all civilization. This is the subject which undisputed forms the very basis of entire world's commercial system. It is a contributory factor in the prosperity of human race. There is no mathematics, no art and no profession, where science does not held a key position. The accuracy and exactness of a thing is determined to a major extent by the amount of science utilized in it. Even social sciences like economics, psychology, geography etc. make abundant use of science. The gigantic work of construction of dams, bridges, building of ships, airplanes, bombs etc. are possible only because of the quantitative science. Even in medical area sciences is used to measure the doses, the blood pressure, the rate of the pulse, the body temperature etc.

Academic Achievement has always been given much importance since the origin of formal system of education. In today's competitive world, it is given more importance than ever before. Academic achievement not only facilities the process of role allocation for the social system but opens out avenues for advancement. Perhaps it is a ladder through which a child of today can reach his destination. It is a root for future development. Success in school, therefore, has often been shown to be predictive of success in further education, career, and personal fulfilment. Obviously in the school, great emphasis is placed on academic achievement right from the beginning of formal education. In spite of considerable efforts, achievement of students is not satisfactory. A great difference of performance is found among students.

Academic achievement is a paramount importance particularly in the present social, economic and cultural context. Obviously, in the school great emphasis is placed on achievement right from the beginning of formal education. The school has its own systematic hierarchy which is largely based on achievement and performance rather than quality. Thus, the school tends to emphasize achievement which facilitates among other things, the process of role allocation for the social system.

The world is becoming more and more competitive and quality of performance has become the key factor for personal progress. Parents desire that their children climb the ladder of performance to as high a level as possible. This desire of a high level of achievement put a lot of pressure on students, teachers and institutions and in general the educational system itself. In fact it appears as if the whole system of education revolves around the academic achievement of the students, through various other outcomes are also expected from the system. Thus a lot of time and efforts of the schools are helping students to achieve better in their scholastic endeavours. The importance of scholastic achievement has raised several important questions for educational researchers. What factors promote achievement in students? How far do the different factors contribute towards academic performance? Therefore many factors have been hypothesized and researched upon and researchers have come out with different results, at time, complementing each other but at times contradicting each other.

\section{Conceptual Frame Work}

There was significant difference in science achievement scores between boy and girls in the present study. Linn C. Merle (1989) investigated that male have greater access to science and technical fields and greater earning power than females. Hensley Clementine, Elizabeth Barber (1987) investigated that boys consistently scored lower than girls. Sarkar (1983), Singh (1984) are also supported that male scored higher than boys. Wing and Staver (1997) the study "An empirical study of gender Differences in Chinese students science achievement; found that boy scored higher than girls. Melkonion, Michael (1997) the study was conducted to 
know the effect of gender on science achievement level found that generally female student attained significantly higher grades than their male. Manning, M. Lee (1998) and PinchasTamir (1998) supported that boys like to study math and science that female and achieve hinge scored in sconce. Leader (1992) has also reported the existence of gender differences in science subjects in general as well as in math. According to same findings like Tzuriel David (2010) this study explored barriers to children's achievement in the areas of science, math and engineering

K. Bharti,V. Vand Jayamma, B. (2006) Found that the percentage of marks was found to be more for adolescents with cable connections than those without cable connection. Fernando Espinoza (2009) found that a negative effect on the science achievement of the students. Ennemoser and Schneider (2007) the longitudinal study explored the long term effect of television viewing on the development of children's reading competencies. They found that vocational program viewing was positively correlated with reading achievement.

Every research project deals with the solution of a problem of human interest. Therefore, the researcher has a definite purpose in mind. He has certain specific goals to achieve through his research work. Such specific goals or purposes are technically formed as objectives. Every research study must have some objectives to achieves, without which no research can be conducted. The entire research process is guided by objectives which have been explicitly and precisely spelled out by the investigator in advance.

The present study is aimed at achieving the following objectives:

1. To compare the science achievement of secondary school students on gender basis.

2. To study the relationship of T.V.watching with science achievement of secondary school students.

3. To study the effect of father occupation on science achievement of secondary school students.

4. To study the relationship of science resources available at home and science achievement of secondary school students.

\section{Methods}

The present work is a descriptive study investigating if students' science achievement differed significantly to a group of variables such as Gender, T.V.watching, Father Occupation and Science Resources available at Home. The sample consisted of 2006 students of class IX, selected from 21 schools of central UP in which 1080 were male and 926 were female students. In this study, schools were categorized on the basis of their medium of instructions. For instance, English Medium schools, where pupils in IX are from all socioeconomic strata and are admitted through competitions and Hindi Medium schools, where pupils in IX are from all socio-economic strata and are admitted through competitions.

\section{Science Achievement Test}

\section{TOOLS USED}

The achievement test in science for class IX students that is used in the present study was constructed by the investigator. This is a very comprehensive test based on 16common chapters of class VIII science text books of U.P.Board and C.B.S.E. Board. The test consists of 75 items of multiple choice type representing achievement at various areas of science such as physics, chemistry and biology of eighth class of U.P. Board and C.B.S.E. Board. Physics have 35 items, chemistry have 20 items and biology having 20 items. The total score on the test as a whole was used as a measure of achievement in science. All the items in the test were the easy items in the test were arranged in order of difficulty, the easy items being placed in the beginning and this was done to motivate the students. The difficulty values of items in the test between the range of .25 to .85 similarly, each item had a discriminating power greater than 0.30 . The test was based on the latest syllabus prescribed by the directorate of education, U.P. \& NCERT. This test had a fairly high content validity and its reliability is found to be 0.87 .

\section{A Personal and Environmental Information Assessment Questionnaire}

The personal and environmental information sheet is prepared by the investigator. This sheet contains such questions requiring the subjects to give information on gender, science resources available at home, father occupation and time spent on watching T.V. etc. 


\section{RESULTS AND ANALYSIS}

\section{1: Relationship between Gender Difference and Science Achievement.}

Data analysis is performed on computer with SPSS 17 software package. When data was analyzed to make a comparative study of the achievement in science of male and female students (Table 1) the result shows a significant difference between achievement in science of males and females $(\mathrm{df}=2004, \mathrm{t}=4.51)$.

The total numbers of male and female students were $1080 \& 926$ respectively as indicated by the table 1 . Out of 75 scores, the mean achievement scores in science of male student is 31.20 and standard deviation $(\mathrm{SD}=12.34)$. In case of female students, the mean science achievement score is 28.75 and standard deviation $(\mathrm{SD}=11.88)$. The statistically calculated t-value is 4.51 ; which is significant at 0.01 levels with $2004 \mathrm{df}$. The result clearly indicates that there is significant difference between mean science achievement score of male and female secondary school students. Both are not equally good they differ in their science achievement. Thus the hypothesis "there is no significant difference between male and female students in science achievement" is rejected at 0.01 level of significance.

The graphical presentation of mean science achievement scores of both sexes is given in figure1.

Table 1: Comparison of mean science achievement scores of male and female students.

\begin{tabular}{|l|l|l|l|l|l|l|}
\hline Gender & N & Mean & SD & df & t-value & Sig./Not sig. \\
\cline { 1 - 5 } Male & 1080 & 31.20 & 12.34 & \multirow{2}{*}{2004} & $4.51^{* *}$ & Sig. at 0.01 level \\
\cline { 1 - 5 } Female & 926 & 28.75 & 11.88 & & & ** Significant at 0.01 level \\
\hline
\end{tabular}

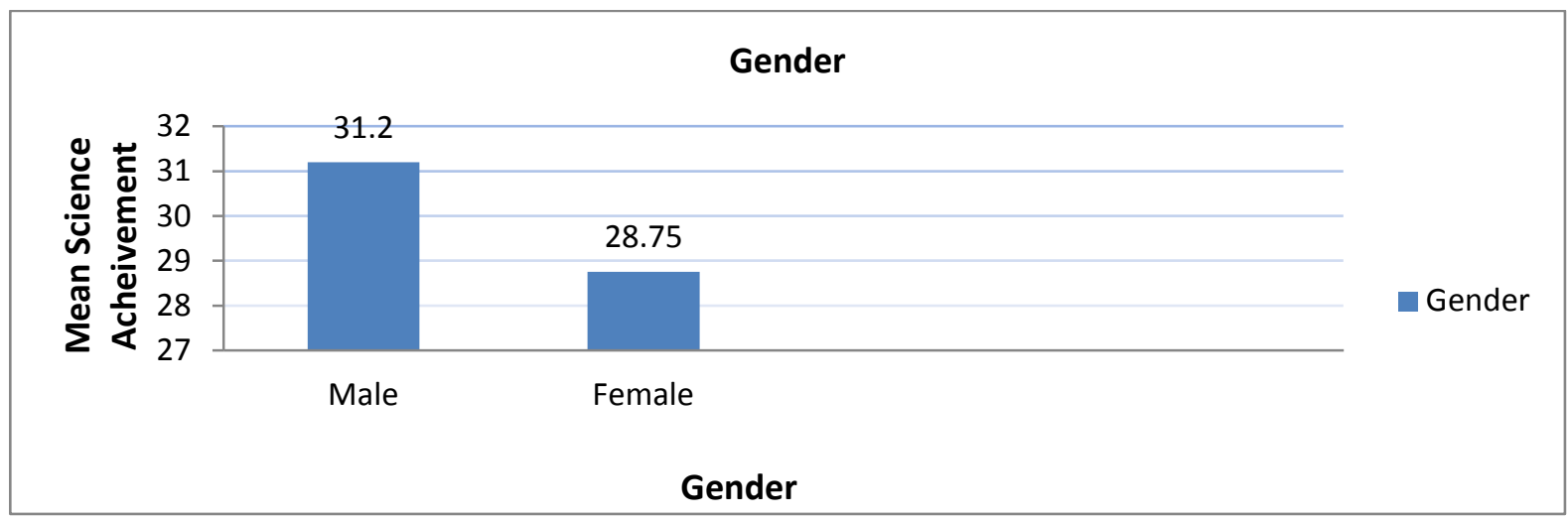

Fig. 1 Gender wise graphical presentation of science achievement.

\section{2: Relationship between T. V. Watching and Achievement in Science of Secondary School Students.}

The total students were divided in to four groups that is zero hours, less than one hours, 1-2 hours, more than 2 hours on the basis of T. V Watching. The scores given that 1, 2, 3 and 4 respectively. Out of total sample (2006) there are 241, 505,1072 and 188 number of students in each groups that is zero hours, less than one hours , 1-2 hours, more than 2 hour respectively.

Table 2 presents the result of relationship between science achievement test and TV. Watching. The means and correlation for both the variables are given in the relevant columns of the table 2 .

The technicians of co-relation are employed to find out the relationship between T.V.watching and achievement in science. The total samples were 2006 (1080 boys and 926 girls). The total samples were categorized in to four groups. i.e. zero hours, less than one hours, 1-2 hours, more than 2 hours on the basis of T.V.watching. The mean scores of T.V.watching and achievement in science is 2.60 and 30.07 respectively, where as the standard divination (SD) of T.V.watching and achievement in science is 0.82 and 12.19 respectively. The estimated correlation coefficient $(\mathrm{r})$ is $0.103 * *$ which is significant at 0.01 level.

The mean score, standard deviation (SD) and correlation coefficient (r) values are shown in table 2.

Hence the results clearly indicate that a strong relationship between the T.V.watching and achievement in science has been demonstrated by these findings. Hence the hypothesis "there is no significant relationship, between T.V.watching and achievement in science of secondary school students" was rejected at 0.01 level of significance. 
Effect of Gender, T.V.watching, Father Occupation and Science...

Table 2Relationship of T.V.watching and mean science achievement scores of secondary school students.

\begin{tabular}{|l|l|l|l|l|}
\hline \multirow{2}{*}{ Variables } & N & & & \\
T.V Watching & 2006 & Mean & SD & Correlation coefficient (r) \\
\hline SAT & 2.60 & 0.82 & $0.103 * *$ \\
\hline
\end{tabular}

\section{3: Relationship between Father's Occupation and Science Achievement of their Children.}

Father's occupation may influence student performance in various ways for example, occupation related to income may determine access to learning opportunities and resources and so play a role in learning outcomes. The education and types of skills associated with different occupations and modelled by parents may motivate students to develop their own skills in particular ways. Father's occupation may also influence how students perceive the value of science learning, their beliefs about the usefulness of science and the learning environment at home. If occupation is considered as an indicator of parental skill, it appears that students whose parents worked in occupation with greater skill requirements also performed better in science. However, the large overlap between groups also indicates that there are still large differences within occupational categories.

To find out the relationship between fathers occupation and achievement in science of their children, the total sample of the students was categorized into four groups on the basis of fathers occupation i.e. agriculturist, professionals, businessman and others. Analysis of variance was employed to determine the significance of differences in science achievement scores of the children of their four groups of fathers. The Fratio came out to be $86.77 * *$ and found to be significant at 0.01 level of significance. This means that there were significant difference in the means of science achievement of the children of agriculturist, professional, businessman and others (table 3).

A glance at the table (3) denotes that the mean achievement scores of children of agriculturist, professional, businessman and others fathers were 26.26, 34.74, 34.44 and 26.60 respectively.

Hence F-test was found significant therefore Duncan's post test was applied for further investigation.

Further support to this conclusion it is also provided by a test of significance of difference between the mean science achievement scores of the four groups of father occupation as given in the table (3).

The statistical method used in testing the major hypothesis was the Duncan's post hoc test for the deference between the means of four groups of father's occupation. The significant pairs obtained by comparing each groups mean science achievement scores with that of every other groups show that out of four possible parried compressions all fours should significant differences.

From the trend it is quite clear that children's of professional groups have highest score in science than other three groups and on the other hand children of low occupational status. Agriculturists have lowest scores in science than other three groups. Children of businessman have more achievement in science than the children of others and agriculturist and less achievement than the professional groups. Children of others group have less achievement than professional and businessman and more than agriculturist groups. The tendency that becomes clear from the study that father's occupation effects the achievement of their children's in science.

The graphical representation of mean science achievement scores of four different groups of father's occupation is given in figure 2. 
Table 3Comparison of science achievement scores among the four categories of father's occupation $\left(\mathrm{O}_{1}=\right.$ agriculturist, $\mathrm{O}_{2}=$ professional, $\mathrm{O}_{3}=$ businessman, $\mathrm{O}_{1}=$ others) of secondary school students.

\section{(Duncan's Mean Test)}

\begin{tabular}{|c|c|c|c|c|c|c|c|c|c|}
\hline \multicolumn{2}{|c|}{$\begin{array}{l}\text { agriculturist } \\
O_{1}(N=788)\end{array}$} & \multicolumn{2}{|c|}{$\begin{array}{l}\text { professional } \\
\mathrm{O}_{2}(\mathrm{~N}=659)\end{array}$} & \multicolumn{2}{|c|}{$\begin{array}{ll}\text { businessman } & \mathrm{O}_{3} \\
(\mathrm{~N}=237)\end{array}$} & \multicolumn{2}{|c|}{$\begin{array}{l}\text { others } \\
\mathrm{O}_{4}(\mathrm{~N}=322)\end{array}$} & \multirow[t]{2}{*}{$\begin{array}{l}\text { Sig. } \\
\text { pairs }(*)\end{array}$} & \multirow[t]{2}{*}{ F-value } \\
\hline Mean & SD & Mean & SD & Mean & SD & Mean & SD & & \\
\hline 26.26 & 10.49 & 34.74 & 12.88 & 34.44 & 11.63 & 26.60 & 10.59 & $\begin{array}{l}\mathrm{O}_{1} \mathrm{Vs} \mathrm{O}_{2} \\
\mathrm{O}_{1} \mathrm{Vs} \mathrm{O}_{3} \\
\mathrm{O}_{2} \mathrm{Vs} \mathrm{O}_{4} \\
\mathrm{O}_{3} \mathrm{Vs} \mathrm{O}_{4}\end{array}$ & $86.77^{* *}$ \\
\hline
\end{tabular}

** Significant at 0.01 level

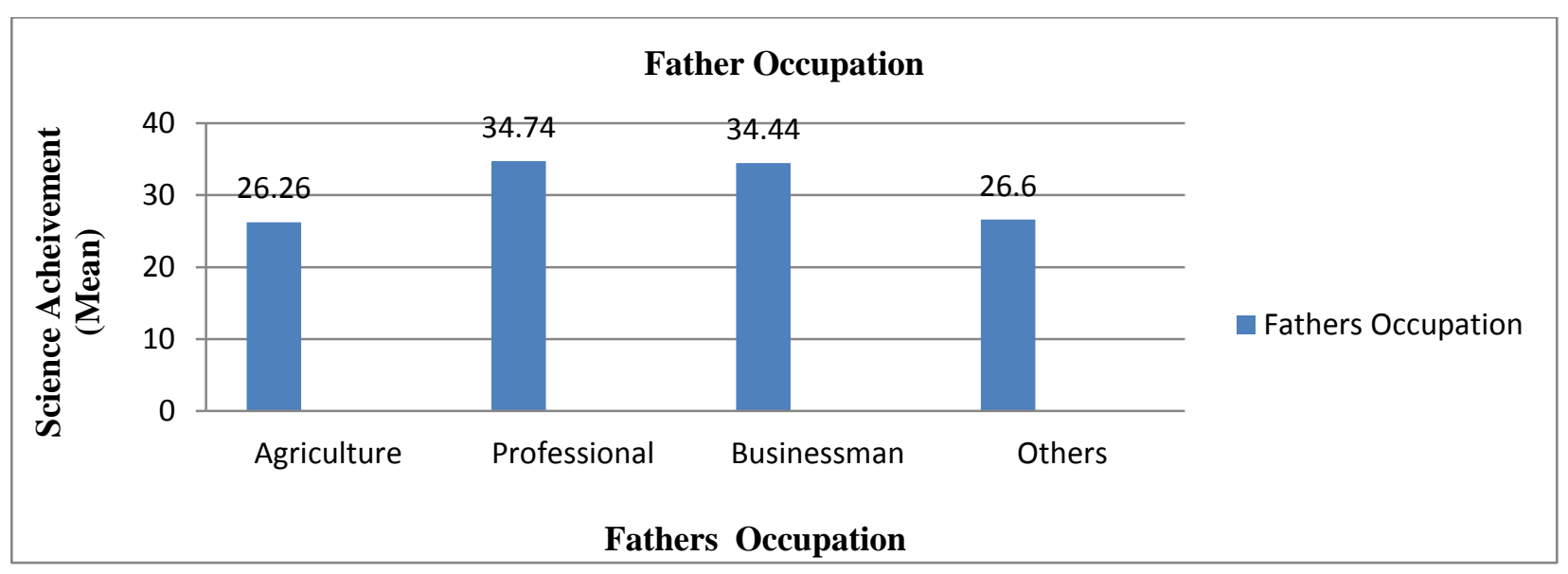

Fig. 2Graphical presentation of mean science achievement scores of four different groups of father's occupation.

Hence the hypothesis "there is no significant difference among the categories of father's occupation and achievement in science of secondary schools students" is rejected at 0.01 level. The results indicate that father's occupation effects the science achievement of their children. Hence there is a positive relationship between father's occupation and their children performance in science.

\section{Relationship between Science Resources Available at Home and Achievement in Science of Secondary School Students.}

Science resources available at home have played an important role in the learning of students. For examine that it was divided in to two parts that is science books and science magazine.

The total students were divided into two groups that is yes and no on the basis of science resources available at home. The scores given in them 1 and 2 respectively. Out of total sample (2006) there is 1800 and 206 number of students in the group yes and no in the reference of science book and in the category of science magazine there is 1605 and 401 student in the group yes and no respectively.

\subsection{Relationship between Science books available at home and achievement in Science of secondary school students.}

The technique of correlation is employed to find out the relationship between science books and achievement in science. The total samples were 2006 (1080 boys and 926 girls).

The total samples were categorized in to two groups i.e. yes and no on the basic of science books available at home. The mean scores of science book and achievement in science is 0.90 and 30.07 respectively, Where as the SD of science books and achieving in science is 0.30 and 12.19 respectively.

The employed correlation coefficient (r) is $0.111^{* *}$, which is significant at 0.01 level. The mean score, standard deviation (SD) and ' $r$ ' values are given in table 4.1. 
Effect of Gender, T.V.watching, Father Occupation and Science...

Table 4.1 Relationship of science book available at home and mean science achievement scores of secondary school students.

\begin{tabular}{|l|l|l|l|l|}
\hline Variables & N & Mean & SD & Correlation coefficient (r) \\
\cline { 1 - 3 } SB & 2006 & 0.90 & 0.30 & \multirow{2}{*}{$0.111^{* *}$} \\
\hline SAT & 2006 & 30.07 & 12.19 & $* *$ Significant at 0.01 level \\
\hline
\end{tabular}

Hence the results clearly indicate that a strong relationship between the science book and achievement in science has been demonstrated by the findings.

4.2. Relationship between Science magazines available at home and achievement in Science of secondary school students.

The total sample was categorized in to two groups that is yes and no on the basis of science magazines available at home. The mean score of science magazines and achievement in science is 0.80 and 30.07 respectively. Whereas the SD of science magazines and achievement in science is 0.40 and 12.19 respectively.

The employed correlation coefficient $(r)$ is $0.075^{* *}$, which in significant at 0.01 level. The main score, standard deviation (SD) and ' $r$ ' values are given in table 4.2.

Hence the results clearly indicates that a strong relationship between the science Magazines and achievement in science has been demonstrated by this findings.

Table 4.2 Relationship of science magazines available at home and mean science achievement scores of secondary school students.

\begin{tabular}{|l|l|l|l|l|}
\hline Variables & N & Mean & SD & Correlation coefficient (r) \\
\hline SM & 2006 & 0.80 & 0.40 & \multirow{2}{*}{$0.075^{* *}$} \\
\hline SAT & 2006 & 30.07 & 12.19 & \\
\hline
\end{tabular}

Hence the overall results clearly indicates that a strong relationship between science resources available at home and achievement in science of students. Hence the hypothesis "there is no significant relationship between science resources available at home and achievement in science of secondary school students" was rejected at 0.01 level of significance.

\section{DISCUSSION}

The purpose of the present research was to determine the effect of gender, t.v.watching,and father occupation and science resources available at home on science achievement of secondary school students of central U.P. There four variables were chosen for analysis because they are manipulable variable that they have been identified as important influences on achievement in previous researches. Data from a large contemporary sample of IX class students were analyzed.

F test followed by Duncan's mean test, Correlation coefficient and T-test were used to determine the effects of these variables on academic achievement, while controlling for other relevant background influences.

The results of the analysis of data shows that the effect of gender, t.v.watching, father occupation and science resources available at home all had significant effect on science achievement scores.

There was significant difference in science achievement scores between boy and girls in the present study. The finding of this study in supported by linn C. Merle (1989) investigated that male has greater access to science and technical fields and greater earning power than females. The national assessment of educational progress and 'Every bad counts': reports that male were found to show higher motivation levels than females.

Hensley Clementine, Elizabeth Barber (1987) investigated that boys consistently scored lower than girls. Sarkar (1983), Singh (1984) are also supported that male scored higher than boys. Wing and Staver (1997) the study "An empirical study of gender Differences in Chinese students science achievement found that boy scored higher than girls. Melkonion, Michael (1997) the study was conducted to know the effect of gender on science achievement level found that generally female student attained significantly higher grades than their male. Manning, M. Lee (1998) and PinchasTamir (1998) supported that boys like to study math and science that female and achieve hinge scored in sconce. Leader (1992) has also reported the existence of gender differences in science subjects in general as well as in math. According to same findings like Tzuriel, D (2010) this study explored barriers to children's achievement in the areas of science, math and engineering. A gender difference in 
girls special abilities emerges very early in development. In that the two groups' one is training program and other is controlled group, after eight weeks he found there are gender difference in the first group.

The results presented support the idea that T.V.watching brings some benefits for students. The result shows that watching T.V. for less than one hour having one fourth of the population and half of population watches T.V. One to two hours and rest of population watching T.V. more than two hours. The analysis shows that watching T.V. by the students having effect their performance in science.

The study supported by this are MichaRazel (2001) found that as small amount of viewing, achievement increased with viewing, but as viewing increased beyond certain point, achievement decreased. Anuradha . K. Bharti,V. VandJayamma, B. (2006) Found that the percentage of marks was found to be more for adolescents with cable connections than those without cable connection. Fernando Espinoza (2009) found that a negative effect on the science achievement of the students. Ennemoser and Schneider (2007) the longitudinal study explored the long term effect of television viewing on the development of children's reading competencies. They found that vocational program viewing was positively correlated with reading achievement.

In this study it is found that father's occupation was related to academic achievement in science. The nature of father's occupation is important for their children in science achievement. Children of professional groups (Engineer, Doctor, Businessman etc.) fathers have got highest science scores than all other groups. Children of business man groups have got more science achievement than other two groups, but less than the children of professional groups. The children of other groups (Peon, Coli, Dailyand Wagers etc.) have god more achievement than the children of agriculturist. The result clearly shows, children of professional groups have got highest achievement and on the other hand children of agriculturist have got lowest achievement in science.

The results supported by white (1982) studies the relationship between SES and academic achievement, he was found that SES in correlated with academic achievement, Bear found that parental occupation was related to academic success. Ibrahim (1996) found that there is a negative relationship between SES (Mother income, occupation and education) and academic achievement.

Science resources available at home play an important role in the learning and achievement of students. In this the resources like, science books, science magazines etc., if available at home then the achievement of students is increases. Pamela E Dan's- Kean (2005) found that socioeconomic status specifically parents education and income, indirectly related to children's academic achievement. Hefferth SL (2010) the study provides a national picture of the time American 6 to 12 yearsolds spent playing video games, Using the computer and watching T.V. at home and their achievement, he found that there is aggressive behaviour to solved the problems and improved their academic achievement.

\section{DELIMITATIONS}

It is not possible in a single research study to cover every aspect of variables associated with the problem under investigation. Although, the problem is very natural and is prevalent everywhere yet due to shortage of time \& resources all the aspects variables could not be covered \& the study is limited in several ways. It had to be determined in terms of population covered, sample selected, scope of variables studied, the scope of genralizability of finding \& so on.

Due to the shortage of time \& resources the study was carried out only on students of class $9^{\text {th }}$ although problem of achievement is common to elementary classes yet the focus of the study has been on the secondary stage only.

1. The sample was restricted to rural and urban areas of central U.P. only so as to make an in-depth study of the factors that affect achievement in science in these schools.

2. The phenomenon of achievement has been studied on in relation to selected personal and environmental variables only.

3. The scope of study covers only a few districts of central U.P. as the investigator felt that no study had been conducted in this area. Hence the generalizability of the findings would be limited accordingly.

4. The tool for the assessment of the achievement in science is developed by investigator himself. Although attempt has been made for proper item selection, try out, estimation of reliability and validity of the tool, detailed norms still remain to be prepared.

5. It is desirable that the researcher reaches first hand or original sources for the study, but as access to some material was not possible materials taken from available secondary sources has been used.

6. Collecting of data in two sitting may be one more delimitation as a number of students are present only in one of the two sessions. Through a third visit is made to cover such students, some drop outs still remain beyond reach of the investigator and have been dropped from the study. 


\section{REFERENCES}

[1] Manning, M Lee (1998), Gender differences in young adolescents' Mathematics and science achievement, childhood education Article.

[2] Meckonion Michael (1997), "The effect of age position and sex on academic performance: a study of secondary school in Cyprus Educational Research, 39 (3). Anuradha, K., Bharthi, V.V. and Jayamma, B. (2006) television viewing behaviour of adolescents-its impact on their academic achievement. Educational Tracks. Vol.6. No.7, pp.27-31.

[3] Tzuriel, D., Egozi, G.(2010). Gender differences in spatial ability of young children: the effects of training and processing strategies. Child development,81 (5), 1417.

[4] TamirPimchas,(1998) Gender differences in high school sciences in Israel, British Educational Research Journal (19).

[5] Barry, J. Fraser and Jane Butler Kahle (2007) Classroom and peer environment influence on students outcomes in Science and Mathematics, An analysis of systematic reform data. International Journal of Science Education, Vol. 29, No. 15, 3, pp. 1891-1909.

[6] Yoloye, E.A. (1998) Students' gender and science achievement: Historical perspective and their present and future practice In Maido, P. \& Savage, M. (Eds), African Science and technology in the new millennium. Cape twon: Iymta\& Co.

[7] Yound, Diedraj and Fraser, B.7. (1994), "Gender difference in science Achievement: Do school Effects make a Difference". Journal of Research INS Science Teaching, vol. 31, Pp, 857-871.

[8] Ennemoser, M and Schneider, W (2007) relations of televisions viewing and readings. Finding from 4 years longitudinal study. Journal of educational Psychology, 99(2), 349 - 368.

[9] Irawin, L.Ramsay: Science and mathematics in today's School. School Science and Mathematics Co., P-1, Dec.1968.

[10] ISKAL, MIME, GAKIROU, ENDINC, Journal of school science and Math's March 2008.

[11] Kothari Commission,1966-68 (Page No. 198)

[12] Krishnan, D.K, \&SankaranNamboodiri, K. (1994) family variables and educational status of the adhivasis of wynad. The Educational Review, (7), 113-115.

[13] White, K.R. (1982). The relation between socio economic status and academic achievement. Psychological bulletin, 91(3), 461-481.

[14] KusumSingh (2002); Mathematics and Science Achievement, effects of Motivation, Interest, and Academic Engagement. The Journal of Educational Research. Volume 95, Number 6/July/August 2002,Pages 323-332

[15] Steven L. Gortmaker; Charles A. Salter, Deborah K. Waler and William H. Dietz Jr. The impact of television viewing on mental aptitude and achievement: A longitudinal study. The American Association for Public Opinion Research. Journal of family psychology, volume 19, issue 2, June 2005. Page 294-304

[16] Nagarju, M.T.V. Sumalathal K. \& Reddy, V.g. (2002). "A study of academic achievement of senior intermediate students in relation to certain factors" The Educational Review, 46(2).

[17] NCERT (1988) NationalCurriculum for elementary education and secondary education-A framework 1988.

[18] Sarkar, U, (1983). "Contribution of science home factors on children's school achievements" Ph.DPshychology, Culcutta University, 1983, Buch M.B. IV survey of Research in Education, $1983-88$ NCERT, New Delhi.

[19] T.S. Begum and Dr. (Mrs.) M. Phukan (2000) A study of some socio-economic factors on Academic Achievement of class on Academic Achievement of class IX students, Asian Journal of psychology and education. Vol. 33, No. 3-4, year 2000, page $17-22$

[20] TIMSS (2007),"Homework and pupil achievement in Norway”. Report1/2010 